\title{
Numerical Simulation for Comparative Thermo-Hydraulic Performance of Turbulent Flow in Tubes with Twisted Tape Inserts
}

\author{
Taye Stephen Mogaji ${ }^{*}$, Emmanuel Tolulope Idowu ${ }^{1}$ and Tien-Chien Jen ${ }^{2}$ \\ ${ }^{1}$ Department of Mechanical Engineering, Federal University of Technology \\ Akure, School of Engineering and Engineering Technology, \\ PMB 704, Ondo State, Nigeria \\ ${ }^{2}$ Department of Mechanical Engineering Science, Faculty of Engineering and \\ the Built Environment, University of Johannesburg, South Africa \\ "Corresponding author: mogajits@gmail.com
}

Published online: 10 December 2020

To cite this article: Taye Stephen Mogaji, Emmanuel Tolulope Idowu and Tien-Chien Jen (2020). Numerical simulation for comparative thermo-hydraulic performance of turbulent flow in tubes with twisted tape inserts. Journal of Engineering Science, 16(2), 71-100, https://doi.org/10.21315/jes2020.16.2.4.

To link to this article: https://doi.org/10.21315/jes2020.16.2.4

\begin{abstract}
This article focused on investigating numerically the effects of key design parameters including tape thickness, tube wall to tape edge clearance and three different perforated shapes cut (circular, triangular and pentagon) on the heat transfer coefficient enhancement in tube with twisted tape inserts. Water was considered as the working fluid under the turbulent flow of Reynolds number (Re) between 12,000 and 22,000, with constant wall temperature of the tubes. It is found that due to the swirling flow and efficient mixing of the fluid, all the tape inserts considered in this study produced better thermalhydraulic performance than the plain tube without an insert. At the same time, tape inserts with small tube wall to tape edge clearance and considerable thickness value is beneficial to reduce the friction factor, consequently enhancing the heat transfer rate. Through the thermal performance factor (TPF) evaluation, the twisted tape with perforated triangular shape cut has an advantage over the pentagon and circular shapes cut with increasing Re. A maximum TPF as high as 1.68 can be obtained for the twisted tape with perforated triangular shape cut under low turbulent Re.
\end{abstract}

Keywords: twisted tape, thickness, clearance, shape-cut, thermal performance factor 


\section{INTRODUCTION}

Improving the rate of heat transfer with an eye on enhancing thermal system efficiency is an important area that has been widely studied in recent time and has led to various developments in several heat transfer enhancement techniques. In most cases, heat transfer enhancement comes with a price of pressure drop increment, which consequently increases the energy consumption. Studies of different approach have been conducted by several researchers in the open literatures to provide a good judgement in terms of geometry selection, which can result in economical and efficient performance of the thermal system. As pointed out in the studies of Kumar and Murugesan ${ }^{1}$ and Mashoofi et al., ${ }^{2}$ the techniques employed in enhancing thermal performance of fluid flow in tube are classified as passive (does not require an external energy), active (require an external energy) and compound (combining two or more of the techniques simultaneously) methods. The passive method is commonly adopted and achieved by using nanofluids (as the working fluids), finned tubes, flute and turbulators. According to Tamna et al., ${ }^{3}$ turbulators are turbulent promoter devices widely employed in heat transfer enhancement in the form of swirling/vortex flow. They are inserted into the tube flow to provide an interruption of thermal boundary layer development, to increase the heat transfer surface area and to cause enhancement of heat transfer by increasing turbulence intensity due to faster fluid mixing. This prompts the development of more compact and economic heat exchanger systems with lower operation cost. ${ }^{3}$ Some of the commonly used turbulators, as reported in the research studies, ${ }^{4-7}$ are wire brushes, coiled wires, longitudinal strip insert, helical screw tape insert and twisted tape inserts. Among these types of turbulators, twisted tape inserts have gained rising attention, due to their advantages of steady performance, simple configuration and ease of installation. ${ }^{5}$ They have also shown to increase significantly the heat transfer coefficient with a relatively small pressure loss penalty. Suri et al. ${ }^{8}$ described a twisted tape as a metallic strip twisted at desired shape and dimension, inserted in the tube to create a swirling flow effect thereby improving the performance of the flow. The advantages attributed to the twisted tape insert pave way for further improvement on this type of turbulator by different researchers. Zhang et al. ${ }^{9}$ carried out a comprehensive and comparative review of self-rotating and stationary twisted tape inserts in heat exchangers. It is worth noting that most of the studies reviewed used air or water as the working fluid. They reported that higher values of TPF, which is a criterion for selecting the optimum twisted tape insert, were obtained with rotating twisted tape. Notwithstanding, stationary twisted tape has prospect of thermal performance improvement when compared with other techniques, which is a promising research direction as reported in the studies of Kumar and Murugesan $^{1}$ and Zhang et al. ${ }^{9}$ Twisted tape inserts have also found their use in 
parabolic trough systems as one of the several research concepts to improve their performance, thereby reducing the cost of energy input (e.g., pumping system) in the systems. Mwesigye et al. ${ }^{10}$ carried out numerical investigation of heat transfer and entropy generation in a parabolic trough receiver with wall-detached twisted tape inserts. It was revealed from their study that twisted tape inserts significantly improve the receiver's heat transfer performance with moderate fluid friction increase.

Bhuiya et al. ${ }^{11}$ conducted experimental study to investigate the heat transfer and pressure drop characteristics in turbulent flow through tube fitted with perforated twisted tape inserts. The porosities of perforation investigated are $1.6 \%, 4.5 \%, 8.9 \%$ and $14.7 \%$ with corresponding pore diameter of $3 \mathrm{~mm}, 5 \mathrm{~mm}$, $7 \mathrm{~mm}$ and $9 \mathrm{~mm}$, respectively. They reported that perforated twisted tape inserts enhanced the heat transfer rate significantly with corresponding increase in friction factor in comparison to that of the plain tube. Recent study on perforated twisted tape inserts by Mashoofi et al. ${ }^{2}$ also revealed that; for larger hole diameters, TPF increases in comparison with plain twisted tape, while small hole diameters gives result close to the plain twisted tape.

The performance of twisted tape inserts for laminar, transitional and turbulent flow regimes have also been investigated by several researchers in the open literature. Flow in a smooth tube is said to be laminar when $\operatorname{Re}<2,300$, transitional when $2,300 \leq \operatorname{Re} \leq 10,000$ and fully turbulent when $\operatorname{Re}>10,000$. However, fully turbulent condition in many practical applications can be achieved even when Re is around 4,000. ${ }^{12}$ Thermo-hydraulic behaviour of an insert depends on the flow regime types regardless of the configuration of the insert. ${ }^{13}$ Effect of Re on performance of twisted tape with different configuration were investigated by Oni. ${ }^{14}$ The range of Re considered were categorise as laminar ( $\operatorname{Re}=830$ to 2,000$)$ and turbulent $(\operatorname{Re}=5,000$ to 20,000$)$. According to Saleh et al., ${ }^{13}$ heat transfer takes place mainly by conduction and molecular diffusion in laminar flow as there is no cross mixing of the fluid, hence resulting in low heat transfer coefficient. Turbulent flow on the other hand induces cross mixing which increases heat transfer coefficient, but with pressure drop penalty. Heat transfer performance evaluation and prediction of correlation for turbulent flow at higher Re was experimentally investigated by Bhuiya et al. ${ }^{15}$ With Re ranging from 7,200 to 50,000, the results indicated that the Nusselt number $(\mathrm{Nu})$, friction factor and TPF were increased with decreasing twist ratio. Nu and $f$-values for the tube with inserts were found to be increased up to $260 \%$ and $285 \%$, respectively in comparison to the plain tube values. Mwesigye et al. ${ }^{10}$ stated that heat transfer irreversibility generally decreases with increasing Re and decreasing twist ratios while the fluid friction irreversibility 
increases with increasing Re and decreasing twist ratios. They further reported that optimal $\mathrm{Re}$ is low at tight twist ratios and high at less tight twist ratios. Similarly, Mashoofi et al. ${ }^{2}$ studied the effect of Re on the perforated twisted tape, their results also revealed that maximum TPF was obtained for largest diameter of $5 \mathrm{~mm}$ and at on Re value of about 16,000.

Despite the numerous experimental studies have been carried out to investigate performance of different twisted tape inserts and with the growing interest due to their high thermal performance, more systematic researches are needed to fully understand the mechanisms associated with the heat transfer coefficient enhancement in tube with twisted tape inserts. More so, they are still limited in making optimum design judgement via visualisation of flow pattern with geometrical variations due to equipment cost and time involved in carrying out such experiments. With a view to alleviate these challenges, adopting numerical simulation in experimental investigation process by using computational fluid dynamics (CFD) tools has been proved to be a very useful method of predicting heat transfer augmentation of fluid flow in tubes. Basically, the major advantage of adopting CFD is that it allows heat transfer and fluid flow simulation in the early stages of design process which ultimately reduces the development cycle while improving performance and cutting costs. Oni and Paul ${ }^{16}$ carried out numerical investigation on the heat transfer and fluid flow of water through a circular tube with different tape inserts. The different tape inserts investigated are plain twisted tape, elliptical cut twisted tape, circular cut twisted tape, triangular cut twisted tape, alternate axis elliptical cut twisted tape, alternate axis circular cut twisted tape and alternate axis triangular cut twisted tape. All the shapes cut on the twisted tape insert have the same area, while twist ratio and tape thickness were also the same for each twisted tape. Their investigation revealed that the shape of cuts has effects on the performance of the twisted tapes, with alternate-axis triangular cut having the best performance. Impacts of the twisted tape geometry variation were also investigated by Oni and Paul. ${ }^{17}$ Alternate-axis triangular cut twisted tape was considered, with varying perimeter of cut on the tape, pitch of the tape and width of the tape. They reported that thermal performance decreases as the pitch increases, but it is augmented by an increase in the size of the cuts on the tape and an increase in the width of the tape. Eiamsa-ard et al. carried out numerical simulation to investigate the swirling flow and convective heat transfer in circular tubes with tight-fit (clearance $=0$ ) twisted tapes and loose-fit (clearance $>0$ ) twisted tapes. Best TPF at constant pumping power was observed for the tight-fit (clearance space ratio, $\mathrm{CR}=0$ ) clearance twisted tape type in their study. However, report from the study by Kumar et al. ${ }^{18}$ involving investigating performance of holes drilled on twisted tape, revealed that drilling or perforating a circular hole on a twisted tape result in a slightly reduced performance than 
the normal twisted tape and it deteriorated further for larger hole diameter. The inconsistency in the observed thermal performance despite different enhancement approach applied by several researchers in the literature depicts that further study is needed for better understanding of the heat transfer enhancement technique. Additionally, thermal performance study on variation in thickness of the twisted tape inserts and variation of area of cut for any considered shapes on twisted tapes, to the best knowledge of the authors, has not been deeply researched in the open literature. The thickness could influence performance and guide in selecting or choosing optimum thickness in addition to twist ratio and shape of cut on twisted tapes. In this study, we considered variation in thickness of the tape inserts, tape edge clearance and shapes-cut: pentagon, circular and triangular on twisted tape inserts. These effects were numerically studied for comparative thermo-hydraulic performance of turbulent flow in tubes with twisted tape inserts.

\section{PHYSICAL AND MATHEMATICAL MODELS}

\subsection{Physical Model}

The three-dimensional (3D) models for the considered geometry in this study were developed in SolidWorks2014 software and imported into Ansys14.0 software for CFD analyses. The dimensions of the initial geometrical model were based on those considered for plain tube (tube without twisted tape insert) and plain twisted tape insert in the study of Oni. ${ }^{14}$ The plain tube has inner diameter $\left(d_{i}\right)$ of $19 \mathrm{~mm}$, outer diameter $\left(d_{o}\right)$ of $21 \mathrm{~mm}$ and length $(L)$ of $540 \mathrm{~mm}$. Figures 1 and 2 present the adopted plain tube and plain twisted tape insert geometries, respectively. The plain twisted tape insert fits into the length of the tube, with width $(H)$ of $18 \mathrm{~mm}$, pitch $(y)$ of $54 \mathrm{~mm}$ and thickness $(\delta)$ of $1 \mathrm{~mm}$. In this study, the length of the tape is taken to be equal to the length of the tube of $L=540 \mathrm{~mm}$. The length was obtained based on twenty pitches resulting from twisting a flat tape. In addition, a clearance $(c)$ of $0.5 \mathrm{~mm}$, which is the distance between the edge of tape and tube wall, and tube thickness $\left(t_{t}\right)$ of $1 \mathrm{~mm}$ were also selected for the first geometry. Numerical simulation was carried out using water as working fluid in a plain tube (PT) (as shown in Figure 1) and twisted tape insert (TI) using different twisted tape insert configurations as shown in Figure 3.

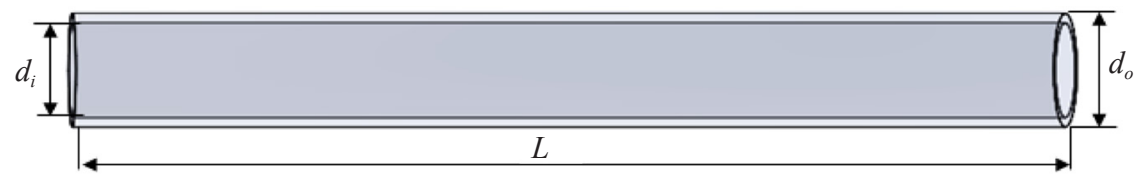

Figure 1: Physical model of plain tube without inserts. 


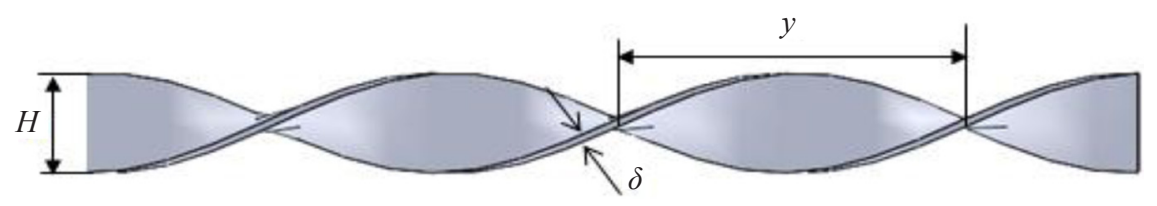

Figure 2: Physical model of a twisted tape.

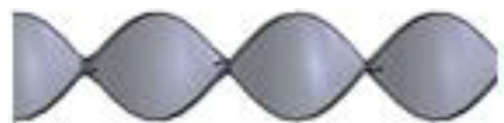

Plain twisted tape

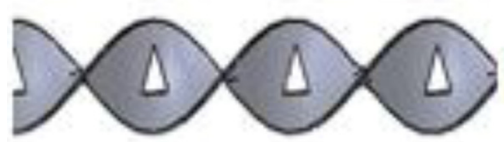

Triangle cut on twisted tape

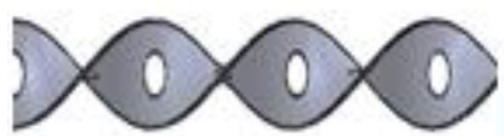

Circular cut on twisted tape

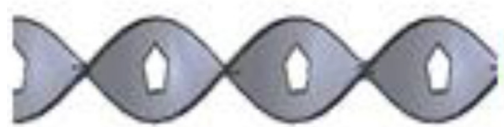

Pentagon cut on twisted tape

Figure 3: Physical model of plain twisted tape and twisted tapes with shape cut.

The dimensions of the shapes (triangle, circle and pentagon) cut on the twisted tape insert are obtained using Equations 1, 2 and 3. The effect of tape thickness ranged from $1 \mathrm{~mm}$ to $2 \mathrm{~mm}$ and tube-wall-to-tape edge clearance ranged from $0.5 \mathrm{~mm}$ to $1 \mathrm{~mm}$ were also investigated for TI. For all the investigations, the inner diameter of tube, length of tube and twisted tape pitch remain unchanged. Width of the twisted tape only varied when the clearance was increased from $0.5 \mathrm{~mm}$ to $1 \mathrm{~mm}$. The twist ratio (tr), which is the ratio of pitch to width of tape, depends on the variation of the width of the tube which consequently depends on the clearance $(c)$ and is expressed in Equation 4. The clearance space ratio $(c r)$ is the ratio of the clearance between the edge of the tape and the tube wall and is estimated using Equation 5. The area of shape-cut for all the geometries on twisted tapes is the same as $A=56.54 \mathrm{~mm}^{2}$.

The area of an equilateral triangle is given by:

$$
A_{T}=\frac{l^{2} \sqrt{3}}{4}
$$


The area of circle is given by:

$$
A_{C}=\pi r^{2}
$$

The area of regular polygon is given by:

$$
A_{p}=\frac{x^{2} n}{4 \tan \left(\frac{180}{n}\right)}
$$

where $l=$ length of a side of equilateral triangle, $r=$ radius of circle, $n$ is the number sides of the polygon (5; pentagon considered in this study) and $x$ is the length of a side of the polygon.

The twist ratio is given by:

$$
t r=\frac{y}{H}
$$

The clearance space ratio is given by:

$$
c r=\frac{2 c}{d_{i}}
$$

\subsection{Governing Equations}

For a three-dimensional models with water flowing in the tube considered to be incompressible and in steady state, and having uniform velocity distribution adopted at the inlet and turbulent; the following assumptions were taken into consideration for the derivation of governing equations: the physical properties of fluid are constant, fluid is incompressible, isotropic, Newtonian and thermal radiation, chemical reaction, compression work and effect of gravity are negligible. Also, since the fluid flowing inside the tube is considered to be fully developed turbulent flow, the Reynolds Averaged Navier-Stokes equations and the averaged energy equation are employed. Hence the continuity, momentum and energy equations, and turbulence models are given as follows:

Continuity equation:

$$
\frac{\partial\left(p u_{i}\right)}{\partial x_{i}}=0
$$


Momentum equation:

$$
\frac{\partial\left(p u_{i} u_{j}\right)}{\partial x_{j}}=\frac{\partial P}{\partial x_{i}}+\frac{\partial P}{\partial x_{j}}\left[\mu\left(\frac{\partial u_{i}}{\partial x_{j}}+\frac{\partial u_{j}}{\partial x_{i}}\right)-\frac{2}{3} \mu \frac{\partial u_{i}}{\partial x_{i}} \delta_{i j}-\rho \overline{u_{i}^{\prime} u_{j}^{\prime}}\right]
$$

Energy equation:

$$
\begin{aligned}
\frac{\partial}{\partial x_{j}}\left(\rho u_{j} c_{p} T\right)= & \left.\frac{\partial}{\partial x_{j}}\left(\lambda \frac{\partial T}{\partial x_{j}}+\frac{\mu_{t}}{\sigma_{h, t}} \frac{\partial\left(c_{p} T\right)}{\partial x_{j}}\right)+u_{j} \frac{\partial P}{\partial x_{j}} \delta_{i j}-\rho \overline{u_{i}^{\prime} u_{j}^{\prime}}\right] \\
& +\left[\mu\left(\frac{\partial u_{i}}{\partial x_{j}}+\frac{\partial u_{j}}{\partial x_{i}}\right)-\frac{2}{3} \mu \frac{\partial u_{i}}{\partial x_{i}} \delta_{i j}-\rho \overline{u_{i}^{\prime} u_{j}^{\prime}}\right] \frac{\partial u_{i}}{\partial x_{j}}
\end{aligned}
$$

where $u_{i}, u_{j}$ are the time-averaged velocity components in the $i$ - and $j$-directions respectively, $\rho \overline{u_{i}^{\prime} u_{j}^{\prime}}$ are the Reynolds stresses $x_{i}, x_{j}$ are spatial coordinates, $T$ is the time-averaged temperature, $P$ is the time-averaged pressure and $\lambda$ is the fluid thermal conductivity. The Reynolds stresses are appropriately modelled by a method that employs Boussinesq hypothesis to relate Reynolds stresses to the mean velocity gradients given as:

$$
-\rho \overline{u_{i}^{\prime} u_{j}^{\prime}}=\mu_{t}\left(\frac{\partial u_{i}}{\partial x_{j}}+\frac{\partial u_{j}}{\partial x_{i}}\right)-\frac{2}{3}\left(\rho k+\mu_{t} \frac{\partial u_{k}}{\partial x_{k}}\right) \delta_{i j}
$$

The term $k$, in Equation 9, is the turbulent kinetic energy per unit mass given by:

$$
k=\frac{1}{2}\left(\overline{u^{\prime 2}}+\overline{v^{\prime 2}}+\overline{w^{\prime 2}}\right)
$$

From literature, no single turbulence models can satisfactorily and reliably predict all turbulent flows with sufficient accuracy. Hence to obtain the optimum prediction of turbulence, the accuracy of two different turbulence models were mostly adopted to give better performance, which are: Realisable $k-\varepsilon$ model and RNG (re-normalisation group) $k-\varepsilon$ model. Each of these models predicted good performances as earlier reported differently by researchers for fluid flow in tubes, but the realisable $k-\varepsilon$ model was often preferred to the RNG $k-\varepsilon$ model as it gave better performance between the two models. ${ }^{5,10,17}$ In view of this, the realisable $k-\varepsilon$ model was adopted in this study.

In the realisable $k-\varepsilon$ model, two additional equations are solved for the transport of turbulent kinetic energy and turbulent dissipation rates and are given in Equations 11 and 12 as follows: 
Turbulent kinetic energy, $k$ :

$$
\frac{\partial}{\partial t}(\rho k)+\frac{\partial}{\partial x_{j}}\left(\rho k u_{j}\right)=\frac{\partial}{\partial x_{j}}\left[\left(\mu+\frac{\mu_{t}}{\sigma_{k}}\right) \frac{\partial k}{\partial x_{j}}\right]+G_{k}-\rho \varepsilon
$$

Turbulent energy dissipation, $\varepsilon$ :

$$
\frac{\partial}{\partial t}(\rho \varepsilon)+\frac{\partial}{\partial x_{j}}\left(\rho \varepsilon u_{j}\right)=\frac{\partial}{\partial x_{j}}\left[\left(\mu+\frac{\mu_{t}}{\sigma_{\varepsilon}}\right) \frac{\partial \varepsilon}{\partial x_{j}}\right]+\rho C_{1} S \varepsilon-\rho C_{2} \frac{\varepsilon^{2}}{k+\sqrt{v e}}
$$

The term $G_{k}$, in Equation 11 represent the production of turbulent kinetic energy and is given by:

$$
G_{k}=-\rho \overline{u_{i}^{\prime} u_{j}^{\prime}} \frac{\partial u_{j}}{\partial x_{i}}
$$

Substituting Equation 9 into Equation 13, we have:

$$
G_{k}=\mu_{t} S^{2}
$$

The eddy viscosity is given by:

$$
\mu_{t}=\rho C_{\mu} \frac{k_{1}^{2}}{\varepsilon}
$$

The turbulent model constants in the realisable $k-\varepsilon$ model are expressed as follows:

$$
C_{1}=\max \left[0.43, \frac{\eta}{\eta+5}\right], \eta=S \frac{k_{1}}{\varepsilon}, S \equiv \sqrt{2 S_{i j} S_{i j}}, C_{2}=1.9, \sigma_{\varepsilon}=1.2
$$

The term $S_{i j}$ represents the rate of linear deformation of a fluid element extracted from Equation 9 and is express as:

$$
S_{i j}=\frac{1}{2}\left(\frac{\partial u_{i}}{\partial x_{j}}+\frac{\partial u_{j}}{\partial x_{i}}\right)
$$

where $\bar{t}$ and $\bar{u}_{i}$ are the time mean values of temperature and velocity and $t^{\prime}$ and $u^{\prime}$ are fluctuating components, $G_{k}$ represents the generation of turbulence kinetic energy due to the mean velocity gradients, $\sigma_{k}$ turbulent Prandtl number for $k$, $\sigma_{\varepsilon}$ turbulent Prandtl number for $\varepsilon, \sigma_{h, t}$ turbulent Prandtl number for energy and $\mu_{t}$ is the turbulent viscosity. 


\subsection{Boundary Conditions}

Water flowing in the tube is considered to be incompressible and in steady state. Uniform velocity distribution was adopted at the inlet. A range of $\operatorname{Re}(12,000 \leq \operatorname{Re} \leq 22,000)$ was considered in this study. The range of $\operatorname{Re}$ was selected to satisfy turbulence flow condition, and to provide possible observations with variation or increase in Re for each geometry. Each corresponding mean velocity of the fluid $(V)$ is obtained from Equation 17 . Hydraulic diameter $\left(d_{h}\right)$ is employed when necessary and could be either for plain tube diameter or tape insert-diameter. Hence inner diameter $\left(d_{i}\right)$ and insert-diameter $\left(d_{t}\right)$ are used in calculating the diameters for the plain tubes and tube with twisted tape insert respectively. The diameter for the tube with tape insert is obtained using Equation 18. Each Re with corresponding mean velocity for flow in plain tubes are presented in Table 1. The turbulence intensity $(I)$ was also estimated using Equation 19 extracted from ANSYS. ${ }^{20}$ The value for temperature of the fluid at inlet was assigned to be $300 \mathrm{~K}$. The thermal properties of the fluid (water): density $(\rho)$, specific heat capacity $\left(c_{p}\right)$, thermal conductivity $(\lambda)$ and dynamic viscosity $(\mu)$ are determined using Equations 20 to 24 extracted from the study of Kays and Crawford ${ }^{21}$ based on the fluid inlet temperature of $300 \mathrm{~K}$ respectively as follow: $996.4 \mathrm{~kg} \mathrm{~m}{ }^{-3}, 4,182 \mathrm{~J} \mathrm{~kg} \cdot \mathrm{K}^{-1}, 0.6115 \mathrm{~W} \mathrm{~m} \cdot \mathrm{K}^{-1}$ and $8.5397 \times 10^{-4} \mathrm{~N} . \mathrm{s} \mathrm{m}^{-2}$. At the tube outlet, only pressure boundary condition was assigned, with gauge pressure set to zero. It is assumed that the tube wall temperature is kept constant at $350 \mathrm{~K}$ all along the entire length of the tube. A no slip condition was also applied to the surface of the tapes and tube wall. Finally, other flow quantities were extrapolated from the interior domain by the solver in Fluent. The summary of simulation parameters considered in the study is presented in Table 2. MATLAB R2015a software was employed to estimate the required parameters in Equations 20 to 24 .

Table 1: Re and mean velocity of fluid $(V)$ for plain tube.

\begin{tabular}{lllllll}
\hline $\operatorname{Re}$ & 12,000 & 14,000 & 16,000 & 18,000 & 20,000 & 22,000 \\
\hline$V\left(\mathrm{~m} \mathrm{~s}^{-1}\right)$ & 0.5413 & 0.6315 & 0.7217 & 0.8119 & 0.9021 & 0.9923 \\
\hline
\end{tabular}

The mean velocity for the fluid flow is estimated from the Re equation expressed in Equation 17:

$$
\operatorname{Re}=\frac{\rho V d_{h}}{\mu}
$$

The tube with tape insert-diameter is given by:

$$
d_{t}=\frac{\pi d_{i}-4 \delta H}{\pi d_{i}+2 H+2 \delta}
$$


Turbulence intensity $(I)$ of the fluid is obtained using Equation 19:

$$
I=0.16 \mathrm{Re}^{-0.125}
$$

Table 2: Summary of the tape geometry and simulation parameters.

\begin{tabular}{lc}
\hline Parameter & Value \\
\hline Tube inner diameter $\left(d_{i}\right)$ & $19 \mathrm{~mm}$ \\
Tube outer diameter $\left(d_{o}\right)$ & $21 \mathrm{~mm}$ \\
Length of tube $(L)$ & $540 \mathrm{~mm}$ \\
Width of tape $(H)$ & $18 \mathrm{~mm}$ \\
Twisted tape pitch $(y)$ & $54 \mathrm{~mm}$ \\
Thickness of tape $(\delta)$ & $1 \mathrm{~mm}, 1.5 \mathrm{~mm}$ and $2 \mathrm{~mm}$ \\
Clearance $(c)$ & $0.5 \mathrm{~mm}, 0.8 \mathrm{~mm}$ and $1 \mathrm{~mm}$ \\
Tube thickness $\left(t_{t}\right)$ & $1 \mathrm{~mm}$ \\
Tube inlet temperature $\left(T_{i n}\right)$ & $300 \mathrm{~K}$ \\
Tube wall temperature $\left(T_{w}\right)$ & $350 \mathrm{~K}$ \\
Area of shape cut $\left(A_{C}, A_{T}\right.$ or $\left.A_{P}\right)$ & $56.54 \mathrm{~mm}$ \\
Re & $1.2 \times 10^{4}$ to $2.2 \times 10^{4}$ \\
\hline
\end{tabular}

The expression by Kays and Crawford ${ }^{21}$ for thermal properties of water, for $278 \mathrm{~K} \leq T_{f} \leq 363 \mathrm{~K}$, are given as follow:

$$
\begin{aligned}
c_{p}= & \left(10.01128-5.135 \times 10^{-2} T_{f}+1.492117\right. \\
& \left.\times 10^{-4} T_{f}^{2}-1.427 \times 10^{-7} T_{f}^{3}\right) \times 10^{3} \\
\operatorname{Pr}= & 899.99-7.78920 T_{f}+2.2641337 \times 10^{-2} T_{f}^{2} \\
& -2.204026 \times 10^{-5} T_{f}^{3} \\
\rho= & 330.116+5.91516 T_{f}-1.631041 \times \\
& 10^{-2} T_{f}^{2}+1.3323 \times 10^{-5} T_{f}^{3} \\
\lambda= & -12.15974+0.1181916 T_{f}-3.6632142 \times \\
& 10^{-4} T_{f}^{2}+3.8084136 \times 10^{-7} T_{f}^{3} \\
v= & 1.083828 \times 10^{-4}-9.330538 \times 10^{-7} T_{f}+2.7027447 \times 10^{-9} T_{f}^{2} \\
& -2.6243211 \times 10^{-12} T_{f}^{3}
\end{aligned}
$$




\subsection{Solution Procedure}

A good simulation results depends on mesh quality, boundary conditions and computational model of the fluid. The procedure and guidelines to achieve these as detailed in ANSYS $^{20}$ were carefully adopted in this study. The numerical simulation was implemented using ANSYS release 14.0, commercial CFD software. The governing equations together with the boundary conditions were solved using a finite volume method (FVM) implemented in CFD code of ANSYS-FLUENT. The FVM discretise the governing partial differential equation. The computational domain was discretised using hexahedral elements with structured elements in the wall normal directions. The coupling of pressure and velocity was done with SIMPLE (Semi Implicit Pressure Linked Equations) algorithm. ${ }^{22}$ Second-order up-wind schemes were employed for integrating the governing equations together with the boundary conditions over the computational domain. The scalable wall function was used for modelling the near-wall regions. The convergence criterion was set to be satisfied when the values of the scaled residuals were in other of less than $10^{-4}$ for the continuity equation, less than $10^{-6}$ for velocity, turbulent kinetic energy and turbulent dissipation rate and less than $10^{-7}$ for energy. The numerical solutions in this study were performed on a computer with Core (TM) i7-5500U CPU at $2.40 \mathrm{GHz}$ and $12 \mathrm{~GB}$ RAM (Random Access Memory) memory and each computation took approximately 8 to $15 \mathrm{~h}$ to converge.

\subsection{Grid Independence Test and Validation of Solution}

Each model developed was imported into ANSYS-14.0 software for grid generation in ANSYS-Meshing environment. In order to obtain results with higher accuracy and almost equal to the existing correlation, vital for validation of computational procedure, grid independence test were carried out. The grid independence test involves the comparison of results obtained from a model, with different grid resolutions or numbers of cells. This could be simply put as investigating how increasing the number of elements will impact the accuracy of a solution. In this study, four different number of cells were used for each domain for the first $\mathrm{Re}$ of $\mathrm{Re}=12,000$. Inlet views of two meshed model are shown in Figure 4, for tube without insert and tube with insert.

Tables 3 and 4 shows the result for grid independence test of plain tube model for $\mathrm{Nu}$ and friction factor, respectively with different number of elements, compared to results estimated from Gnielinski (G) and Dittus-Boelter (D) correlations for $\mathrm{Nu}$, and Petukhov (P) and Blasius (B) correlations for friction factor. The variation of $\mathrm{Nu}$ and friction factor with four different grid sizes are presented in Figures 5 and 6, respectively. 


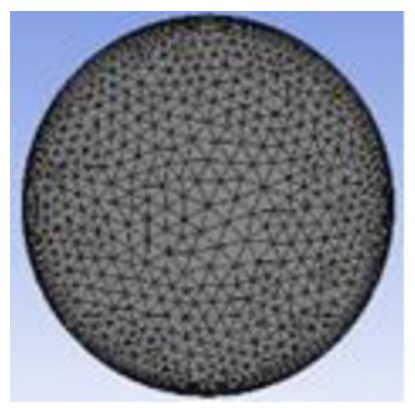

(a)

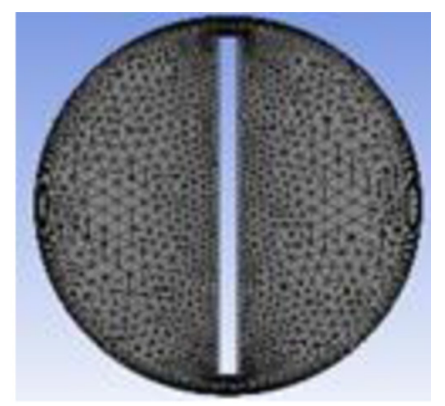

(b)

Figure 4: Inlet views of meshed models (a) without insert and (b) with insert.

Table 3: Grid independence test of plain tube for $\mathrm{Nu}$.

\begin{tabular}{lccccccc}
\hline \multirow{2}{*}{ Number of element } & $T_{\text {out }}(K)$ & $\Delta \mathrm{P}(\mathrm{Pa})$ & & \multicolumn{4}{c}{$\mathrm{Nu}$} \\
\cline { 5 - 7 } 533390 & \multirow{2}{*}{306.7} & \multirow{2}{*}{125.2} & $\mathrm{G}$ & 90.90 & 88.18 & 2.99 \\
& & & $\mathrm{D}$ & 87.86 & 88.18 & 0.35 \\
595323 & \multirow{2}{*}{306.7} & \multirow{2}{*}{124.9} & $\mathrm{G}$ & 90.90 & 88.04 & 3.15 \\
& & & $\mathrm{D}$ & 87.86 & 88.04 & 0.19 \\
686882 & \multirow{2}{*}{306.6} & \multirow{2}{*}{124.1} & $\mathrm{G}$ & 90.90 & 87.75 & 3.45 \\
& & & $\mathrm{D}$ & 87.86 & 87.75 & 0.11 \\
806039 & \multirow{2}{*}{306.6} & \multirow{2}{*}{123.7} & $\mathrm{G}$ & 90.90 & 87.61 & 3.59 \\
& & & & $\mathrm{D}$ & 87.86 & 87.61 & 0.28 \\
\hline
\end{tabular}

Table 4: Grid independence test of plain tube for friction factor.

\begin{tabular}{|c|c|c|c|c|c|c|}
\hline \multirow{2}{*}{ Number of element } & \multirow{2}{*}{$T_{\text {out }}(K)$} & \multirow{2}{*}{$\Delta \mathrm{P}(P a)$} & \multicolumn{4}{|c|}{ Friction factor } \\
\hline & & & \multicolumn{2}{|c|}{ Correlation result } & CFD result & $\%$ diff. \\
\hline \multirow{2}{*}{533390} & \multirow{2}{*}{306.7} & \multirow{2}{*}{125.2} & $\mathrm{P}$ & 0.0293 & 0.0302 & 3.06 \\
\hline & & & $\mathrm{B}$ & 0.0296 & 0.0302 & 1.99 \\
\hline \multirow{2}{*}{595323} & \multirow{2}{*}{306.7} & \multirow{2}{*}{124.9} & $\mathrm{P}$ & 0.0293 & 0.0301 & 2.85 \\
\hline & & & $\mathrm{B}$ & 0.0296 & 0.0301 & 1.79 \\
\hline \multirow{2}{*}{686882} & \multirow{2}{*}{306.6} & \multirow{2}{*}{124.1} & $\mathrm{P}$ & 0.0293 & 0.0299 & 2.15 \\
\hline & & & $\mathrm{B}$ & 0.0296 & 0.0299 & 1.10 \\
\hline \multirow{2}{*}{806039} & \multirow{2}{*}{306.6} & \multirow{2}{*}{123.7} & $\mathrm{P}$ & 0.0293 & 0.0298 & 1.82 \\
\hline & & & $\mathrm{B}$ & 0.0296 & 0.0298 & 0.77 \\
\hline
\end{tabular}




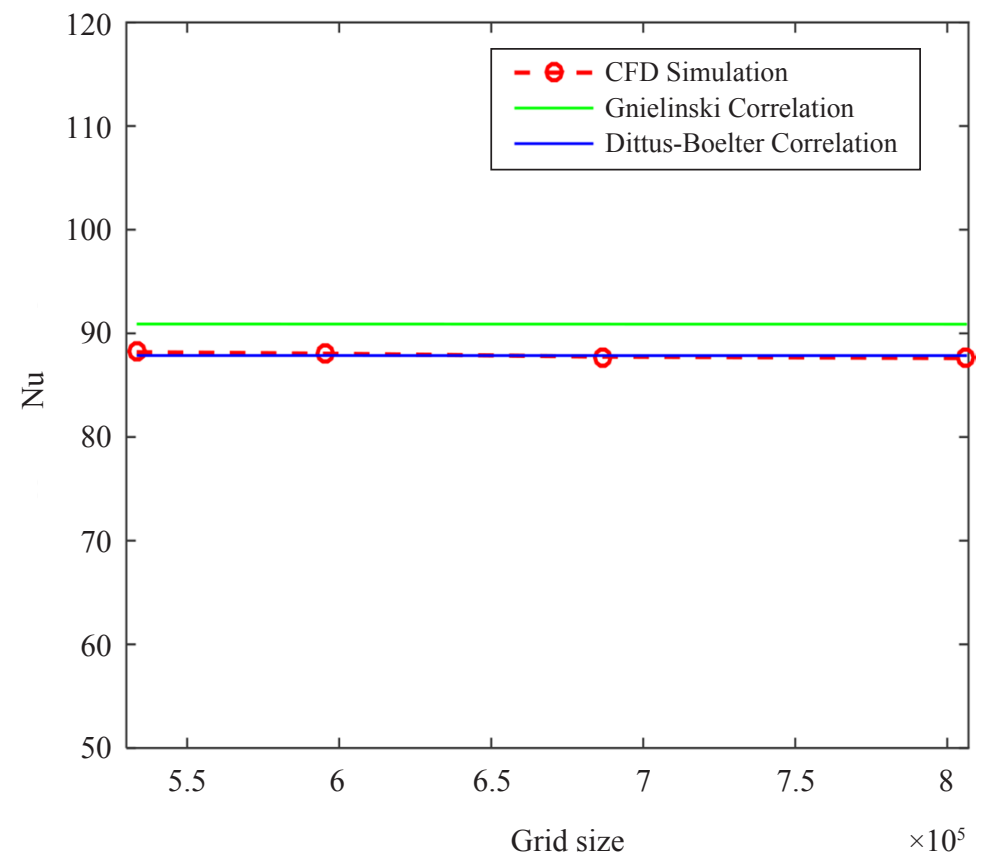

Figure 5: Grid independence test of $\mathrm{Nu}$ for plain tube flow.

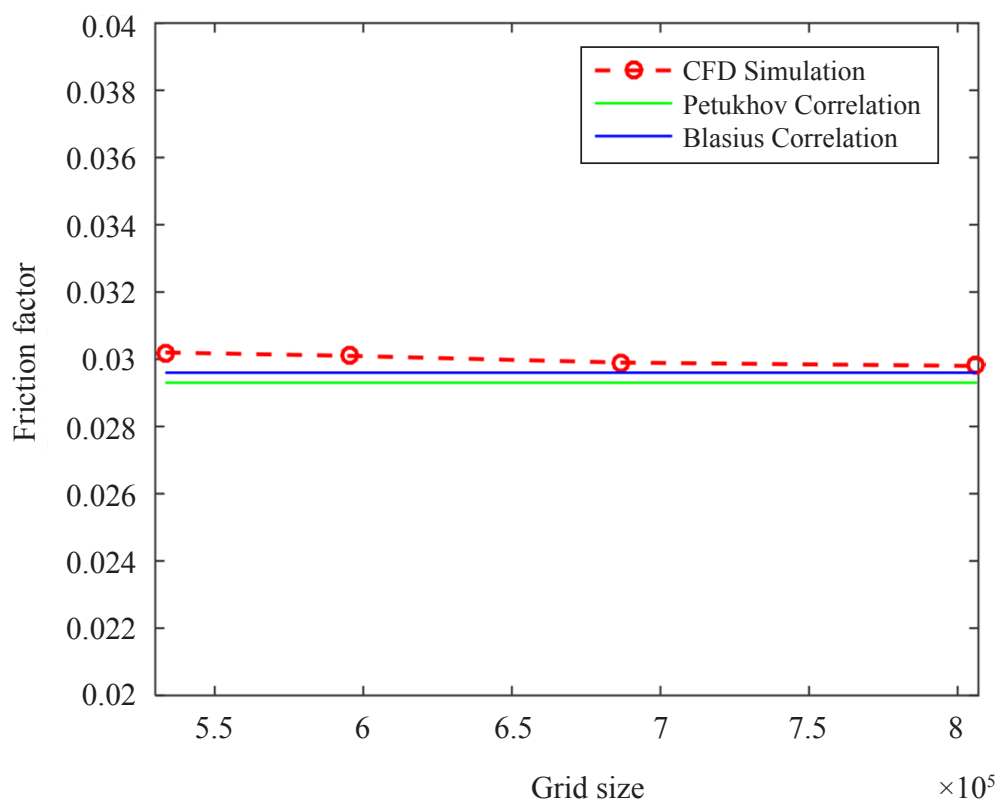

Figure 6: Grid independence test of friction factor for plain tube flow. 
Considering computation time and solution accuracy, the grids are compared for each model to know the grid sizes computed with negligible difference, specifically less than $1 \%$. It was observed that the difference between grid sizes 686882 and 806039 which are the third and fourth grid sizes, respectively was $0.16 \%$ and $0.33 \%$ for $\mathrm{Nu}$ and friction factor, respectively. Hence 686882 grid size was selected for computation of the remaining Re values. Similar approach was followed for grid independence test of the other models (i.e. twisted plain tape and twisted tape with shape-cut). The different grid sizes and the estimated $\mathrm{Nu}$ and friction factor for the third grid sizes (i.e. based on the criterion adopted in selecting grid used for plain tube after observing negligible difference) selected for each geometry are presented in Tables 5 and 6 , respectively. Figures 7 and 8 shows the different grid sizes for the twisted plain tube and twisted tape with shape-cut, and their variation with $\mathrm{Nu}$ and friction factor, respectively. The geometries are represented as twisted plain tape (TI), twisted tape with circular shape-cut (CC), triangular shape-cut (TC) and pentagon shape-cut (PC).

Table 5: Grid independence test of twisted plain tape and tape with shape-cut $\mathrm{Nu}$.

\begin{tabular}{cccccc}
\hline Geometry & \multicolumn{5}{c}{ Number of element } \\
\hline TI & 1649241 & 1706256 & 1749253 & 1769353 & 149.709 \\
CC & 1703184 & 1743675 & 1763082 & 1783081 & 183.585 \\
TC & 1724714 & 1754735 & 1774714 & 1804625 & 187.109 \\
PC & 1797056 & 1807023 & 1827066 & 1887054 & 184.634 \\
\hline
\end{tabular}

Table 6: Grid independence test of twisted plain tape and tape with shape-cut with friction factors.

\begin{tabular}{|c|c|c|c|c|c|}
\hline \multirow{2}{*}{$\begin{array}{c}\text { Geometry } \\
\mathrm{TI}\end{array}$} & \multicolumn{4}{|c|}{ Number of element } & \multirow{2}{*}{$\frac{\text { Friction factor }}{0.0551}$} \\
\hline & 1649241 & 1706256 & 1749253 & 1769353 & \\
\hline $\mathrm{CC}$ & 1703184 & 1743675 & 1763082 & 1783081 & 0.0609 \\
\hline $\mathrm{TC}$ & 1724714 & 1754735 & 1774714 & 1804625 & 0.0611 \\
\hline $\mathrm{PC}$ & 1797056 & 1807023 & 1827066 & 1887054 & 0.0619 \\
\hline
\end{tabular}




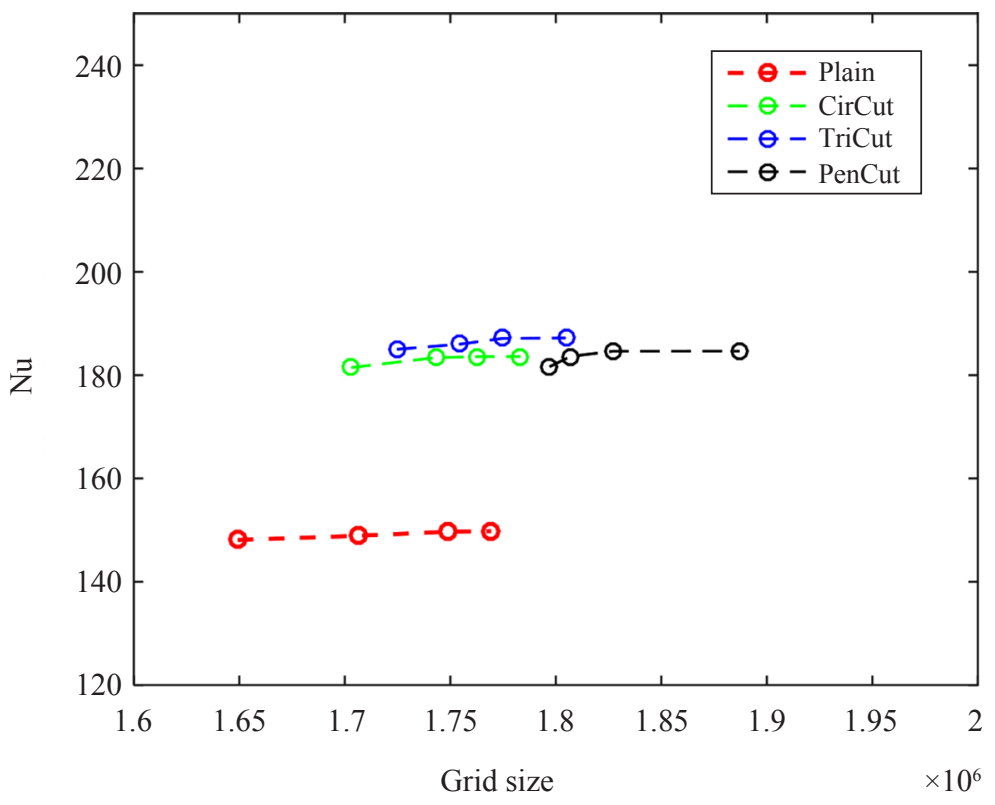

Figure 7: Grid independence test of $\mathrm{Nu}$ for twisted plain tape and twisted tape with shape cut.

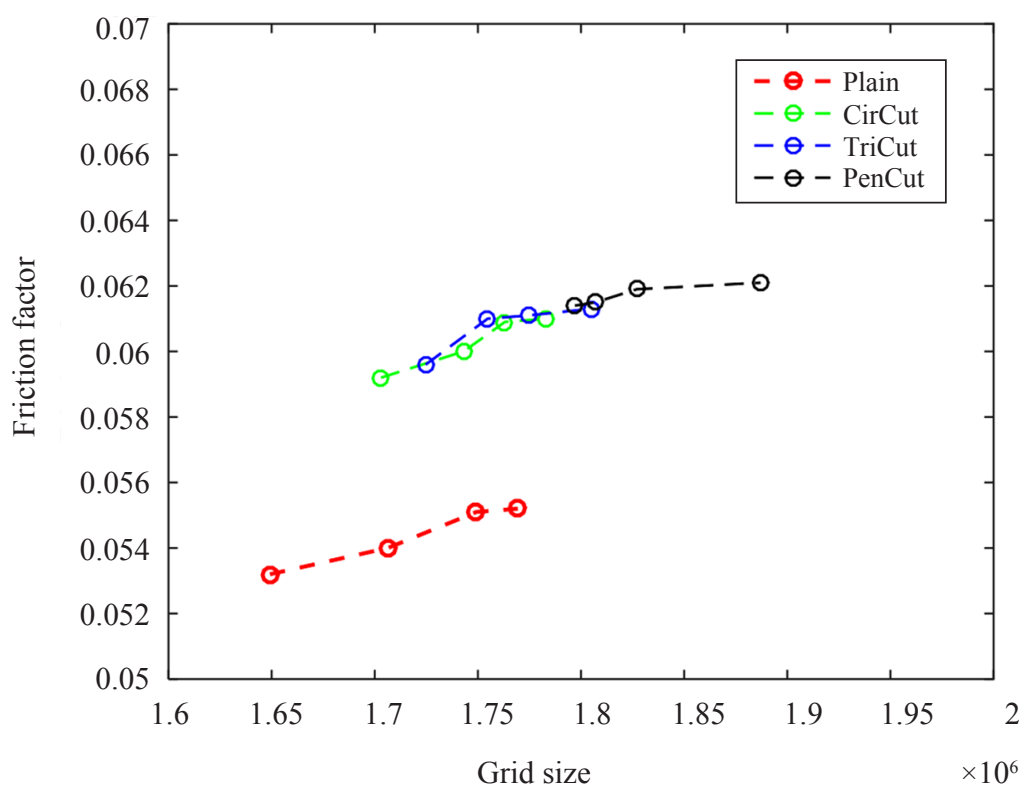

Figure 8: Grid independence test of friction factor for twisted plain tape and twisted tape with shape cut. 


\section{DATA REDUCTION}

The heat transfer rate is given by:

$$
Q_{h}=\dot{\mathrm{m}} \times c_{p} \times\left(T_{\text {out }}-T_{\text {in }}\right)
$$

where $c_{p}$ is the specific heat capacity of the fluid, is the mass flow rate of fluid at the tube inlet condition obtained as follows:

$$
\dot{\mathrm{m}}=\rho V A_{c s}
$$

$A_{c s}$ in Equation 26 is the tube cross-sectional area of the tube, given by:

$$
A_{c s}=\frac{\pi d_{h}^{2}}{4}
$$

$T_{\text {out }}$ is the outlet temperature of fluid, $T_{\text {in }}$ is the inlet temperature of fluid. It is interesting to highlight that the thermo-physical properties of the fluid used for the calculation of heat transfer rate are determined in terms of the average value of the inlet and outlet temperature at the tube ends. Thus, the average temperature referred to as the bulk temperature $\left(T_{b}\right)$ is given by:

$$
T_{b}=\frac{T_{\text {in }}+T_{\text {out }}}{2}
$$

The convective heat transfer for constant wall temperature is given in Equation 29 as extracted from Equation 12:

$$
Q_{c}=h \times A \times \Delta T_{\mathrm{ln}}
$$

In Equation 29, $A$ is the total surface area of the tube, and is given by:

$$
A=\pi d_{h} L
$$

The term $\Delta T_{\ln }$ in Equation 29, is the logarithmic mean temperature difference (LMTD), and is given as:

$$
\Delta T_{\ln }=\frac{\Delta T_{\text {out }}-\Delta T_{\text {in }}}{\ln \left(\Delta T_{\text {out }} / \Delta T_{\text {in }}\right)}
$$

where $\Delta T_{\text {in }}=T_{w}-T_{\text {in }}$ and $\Delta T_{\text {out }}=T_{w}-T_{\text {out }}$. 
According to Cengel, ${ }^{12}$ heat transfer rate is assumed to be equal to the convective heat transfer for a steady state condition, thus equating Equation 25 to Equation 29 we have:

$$
\dot{\mathrm{m}} \times c_{p} \times\left(T_{\text {out }}-T_{\text {in }}\right)=Q=h \times A \times \Delta T_{\text {ln }}
$$

Therefore, the average convective heat transfer coefficient $(h)$ is given by:

$$
h=\frac{\mathrm{Q}}{A \Delta T_{\ln }}
$$

Hence, the average $\mathrm{Nu}$ is calculated as follow:

$$
\mathrm{Nu}=\frac{h d_{h}}{\lambda}
$$

The thermal conductivity $\lambda$ in Equation 34 was evaluated at the bulk fluid temperature condition extracted from Cengel. ${ }^{12}$

The pressure drop $(\Delta P)$ across the tube is obtained as the difference between the average value of pressure at the inlet and outlet cross-sections, respectively given as:

$$
\Delta P=P_{\text {in }}-P_{\text {out }}
$$

Based on the obtained pressure drop, the friction factor is estimated using Darcy friction factor correlation expressed in Equation 36 as:

$$
f=\frac{2 d_{h} \Delta P}{\rho L V^{2}}
$$

In order to determine the optimum condition at which the considered heat transfer enhancement device used in this article is profitable, the TPF relation is implored in analysing the obtained numerical simulation result in this study and is given by Equation 37:

$$
f=\left(\frac{\mathrm{Nu}_{1}}{\mathrm{Nu}}\right)\left(\frac{f_{1}}{f}\right)^{-1 / 3}
$$

where $\mathrm{Nu}$ and $\mathrm{Nu}_{1}$ are the $\mathrm{Nu}$ for the plain tube and tube with insert, respectively, and $f$ and $f_{1}$ are friction factor for the plain tube and tube with insert, respectively. 


\section{RESULTS AND DISCUSSIONS}

\subsection{Comparison of Tape Thickness Effects}

Figures 9(a) and 10(a) show the graphical illustration of thermal performance for flow in plain tube and tube inserted with twisted tape of varying thickness in terms of $\mathrm{Nu}$ and friction factor, respectively.

Figures 9(b) and 10(b) show the static outlet temperature and pressure contour for plain tube and tube with inserts of the three different tape thicknesses at $\mathrm{Re}=12,000$. The comparison results were obtained for flow in tube without insert and tube with twisted tape insert (without shape cut perforation) considering different tape thickness: ( $1 \mathrm{~mm}, 1.5 \mathrm{~mm}$ and $2 \mathrm{~mm}$ ) and Re ranged from 12,000 to 22,000. As expected, higher heat transfer coefficient and larger pressure drop are observed in tube with twisted tape insert independent of their thickness when compared to plain tube without insert. This behaviour is similar to those observed in the following studies. ${ }^{4,10,14,18}$ This behaviour is observed to be more pronounced with tape of thickness, $2 \mathrm{~mm}$ considered in this study indicating that by increasing the tape thickness, the obstruction area created by the inserted tape is increased which improves the flow turbulence of the fluid thereby increasing the pressure drop and enhancing the heat transfer rate.

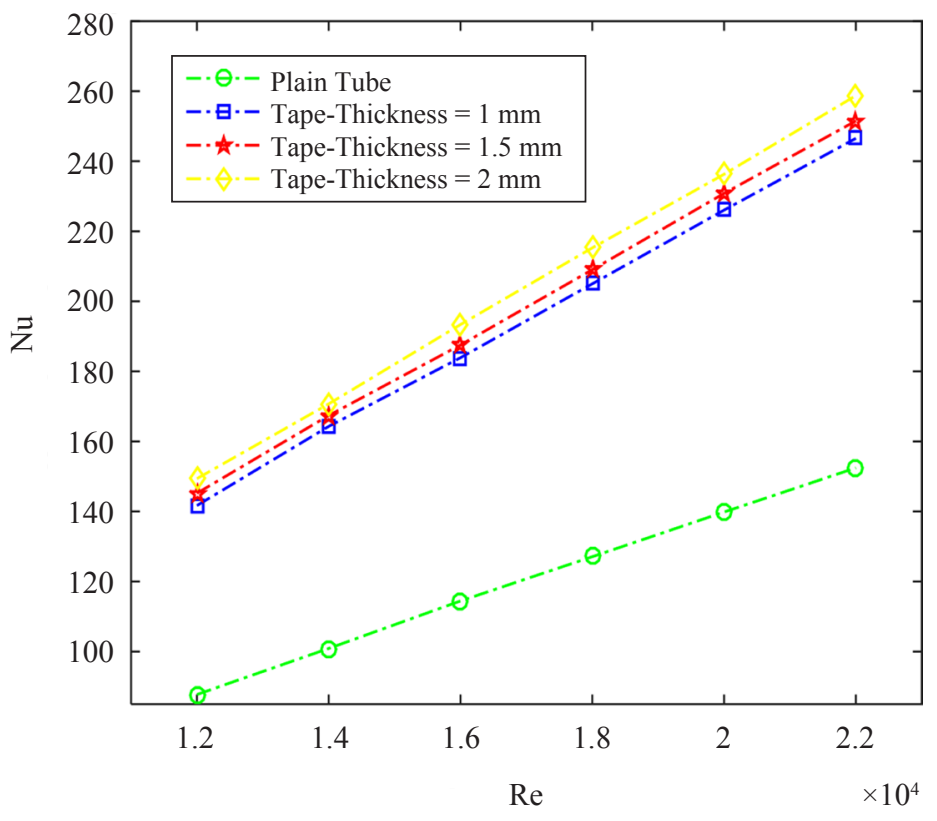

Figure 9(a): Nu vs. Re for different tape thickness. 


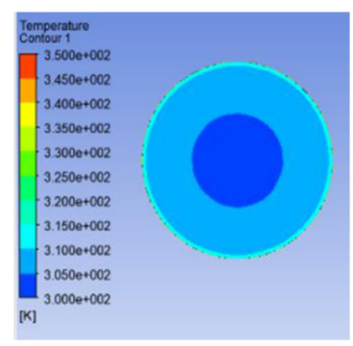

(i)

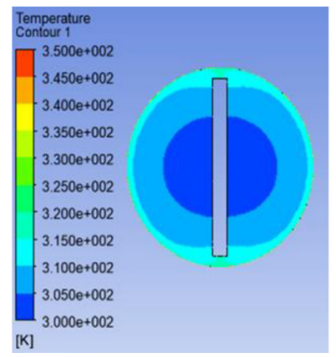

(iii)

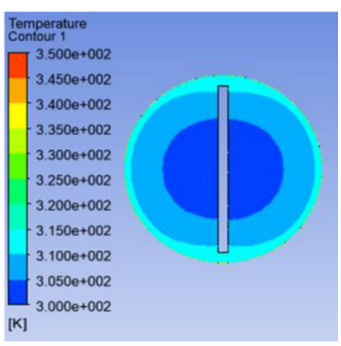

(ii)

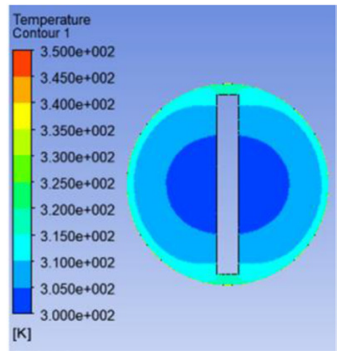

(iv)

Figure 9(b): Temperature contour for (i) plain tube and thickness (ii) $1 \mathrm{~mm}$, (iii) $1.5 \mathrm{~mm}$ and (iv) $2 \mathrm{~mm}$.

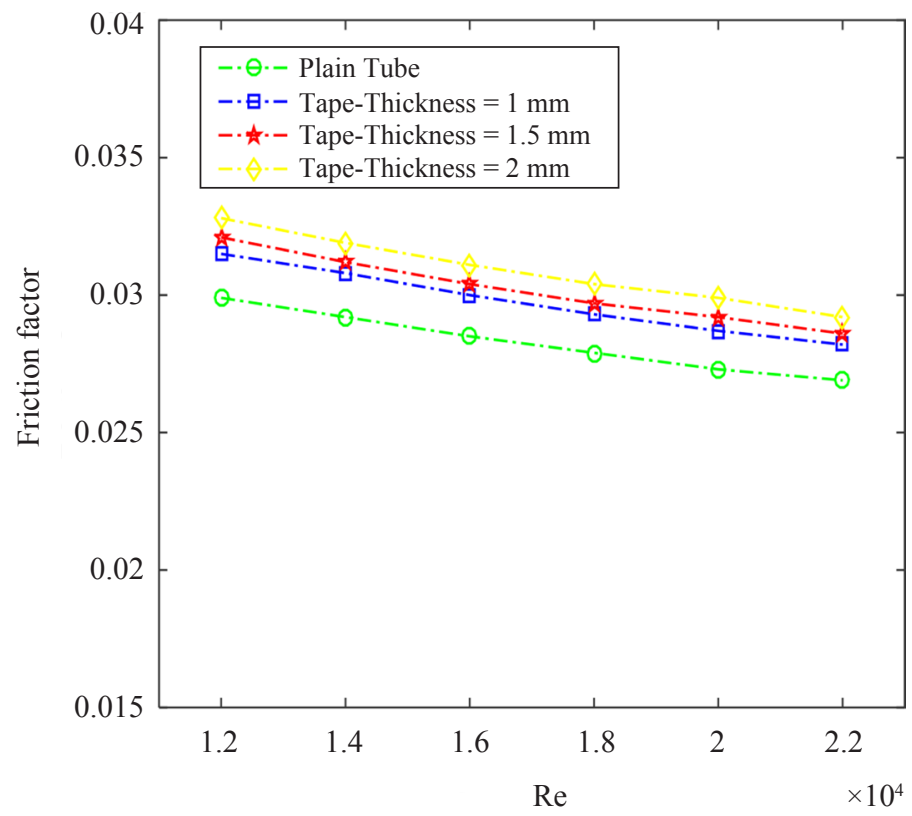

Figure 10(a): Friction factor vs. Re for different tape thickness. 


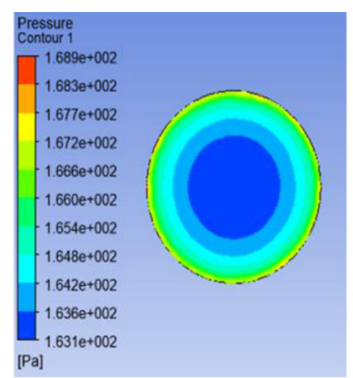

(i)

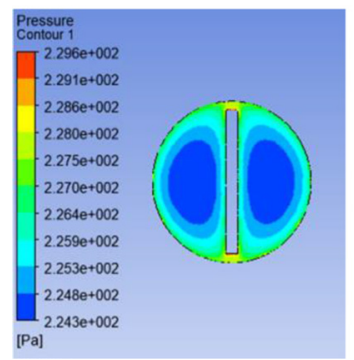

(iii)

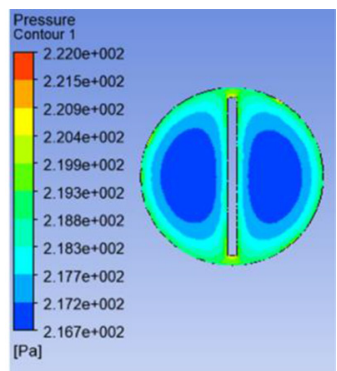

(ii)

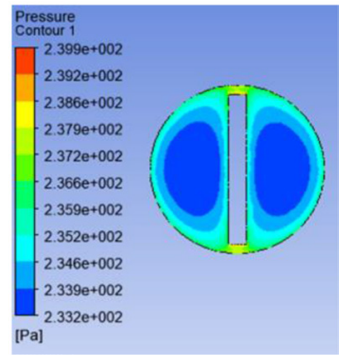

(iv)

Figure 10(b): Pressure contour for (i) plain tube and thickness (ii) $1 \mathrm{~mm}$, (iii) $1.5 \mathrm{~mm}$ and (iv) $2 \mathrm{~mm}$.

In this section, the results obtained for flow in tube with twisted tape of thickness $2 \mathrm{~mm}$, while varying clearance from $0.5 \mathrm{~mm}$ to $1 \mathrm{~mm}$ are considered. Graphical illustration of performance with tape of varying clearance in terms of $\mathrm{Nu}$ and friction factor values are shown in Figures 11(a) and 12(a), respectively. From these figures, it could be noticed that the tape with minimum clearance of $0.5 \mathrm{~mm}$ yield highest heat transfer performance $(\mathrm{Nu})$ with lowest friction factor shown in Figure 12(a). Similar behaviour was observed in a previous study, ${ }^{5}$ where clearance ratio values ( 0 to $0.3 \mathrm{~mm}$ ) was used to indicate tight-fit and loose-fit tape insert, with the findings stating that tight-fit clearance ratio produces higher heat transfer performance. This reveals that better thermal performance could be achieved while the pumping power under this operational condition could be minimal and thus improve the system efficiency. Figures 11(b) and 12(b) show the static temperature and pressure contour at tube outlets for tube with inserts of the three different clearance at $\mathrm{Re}=12,000$. 


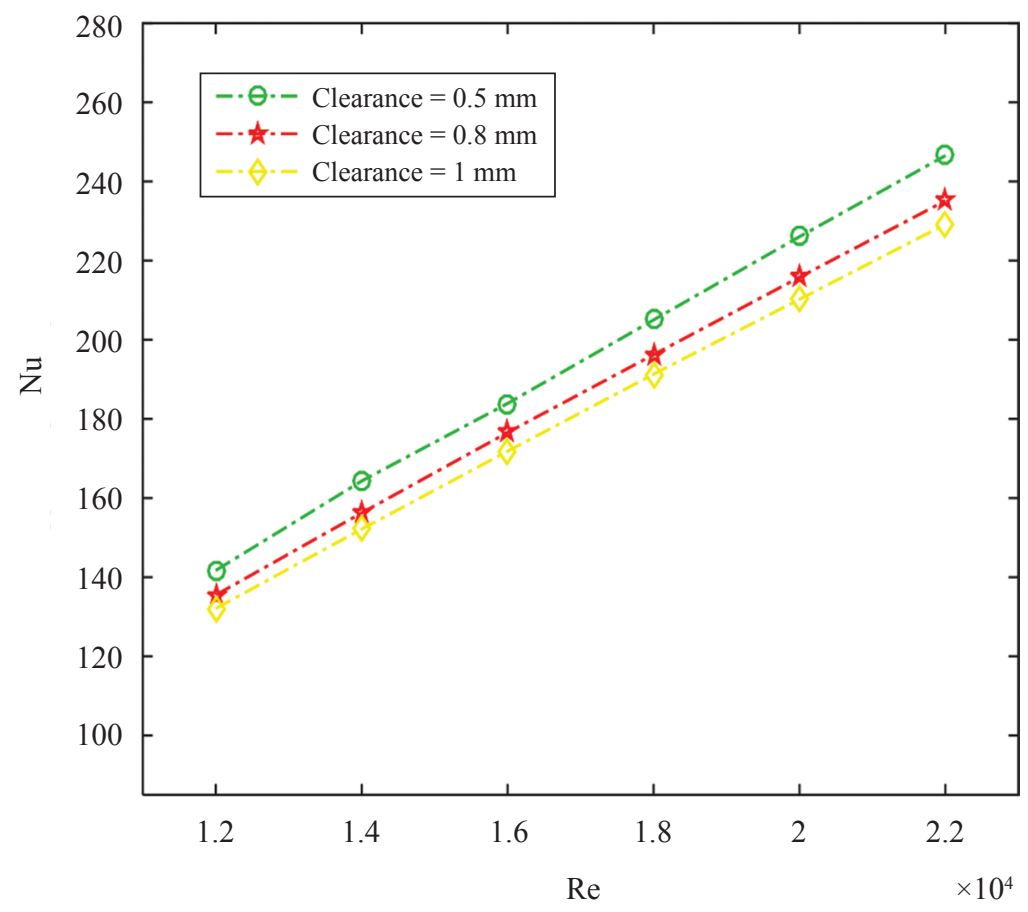

Figure 11(a): Nu vs. Re for different tape clearance.

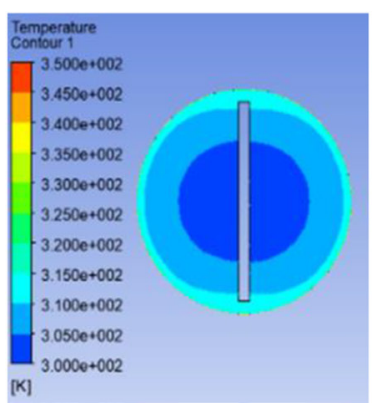

(i)

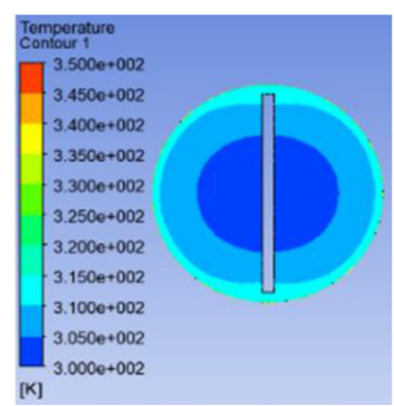

(ii)

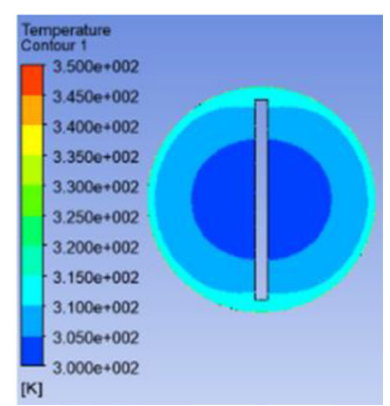

(iii)

Figure 11(b): Temperature contour for clearance; (i) $0.5 \mathrm{~mm}$, (ii) $0.8 \mathrm{~mm}$ and (iii) $1 \mathrm{~mm}$. 


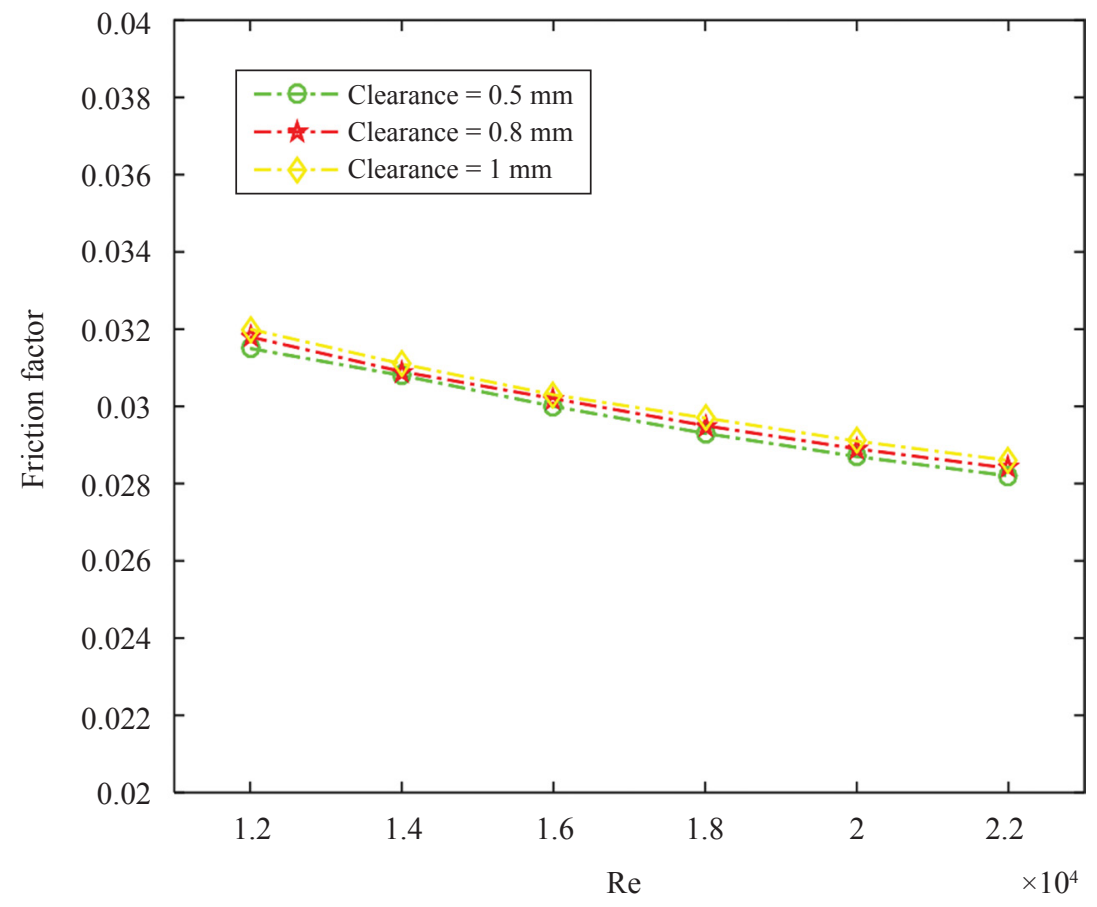

Figure 12(a): Friction factor vs. Re tape inserts for different tape clearance.

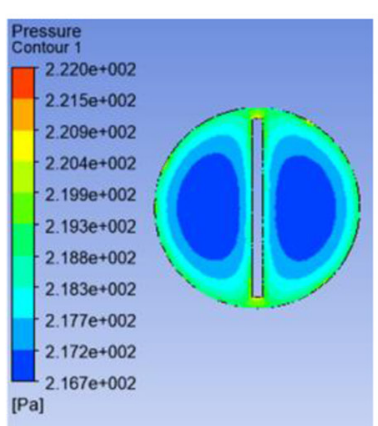

(i)

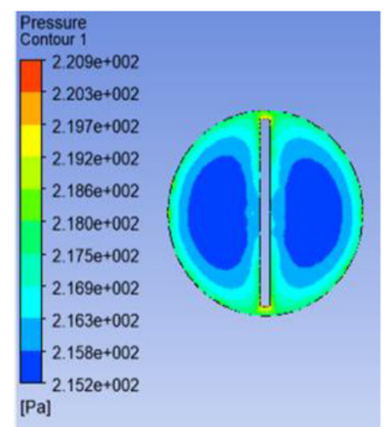

(ii)

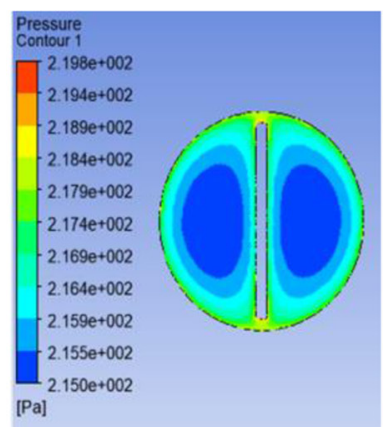

(iii)

Figure 12(b): Outlet pressure contour for clearance; (i) $0.5 \mathrm{~mm}$, (ii) $0.8 \mathrm{~mm}$ and (iii) $1 \mathrm{~mm}$. 


\subsection{Comparison of Shape-cut Effects}

Figures 13 and 14 show variation of $\mathrm{Nu}$ and friction factor with $\mathrm{Re}$ while considering twisted tapes with perforation of three different shape-cut (circle, triangle and pentagon). The following geometry parameters were kept constant; tape thickness of $2.0 \mathrm{~mm}$, clearance of $0.5 \mathrm{~mm}$ and area of shape cut of for all the tapes insert. With the perforation shape cut, the result from this study revealed that triangular shape-cut produces higher $\mathrm{Nu}$ and friction factor than the circular, which is in agreement with the findings of Oni and Paul. ${ }^{16}$ By further comparing the triangular, circular and pentagon shape-cut in this study, it was observed that the triangular shape-cut still gave highest heat transfer performance within the range of Re values considered in this study. It is also noticed that the performance of pentagon and circular shape-cuts increase with increase in Re but better performance is observed for the pentagon shape at the lower Re value up to 14,000 and higher Re values in the range between 18,000 and 22,000 compared to the circular shape. However, the drawback associated with the high $\mathrm{Nu}$ for all perforated shapes is the observed high friction factor values (as shown in Figure 14) compared to unperforated twist tube (as shown in Figure 10[a]). It is also worth noting that the pentagon shape-cut twist tape result gives the highest friction factor values.

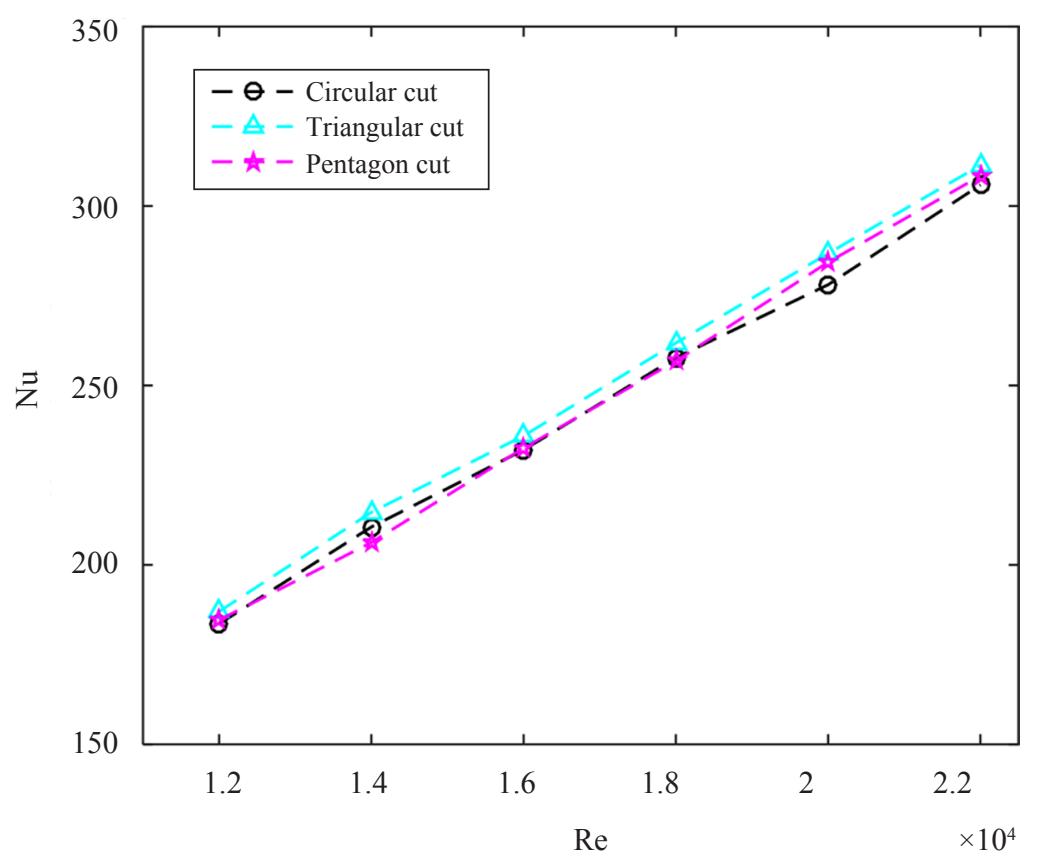

Figure 13: Nu vs. Re for different tape inserts. 


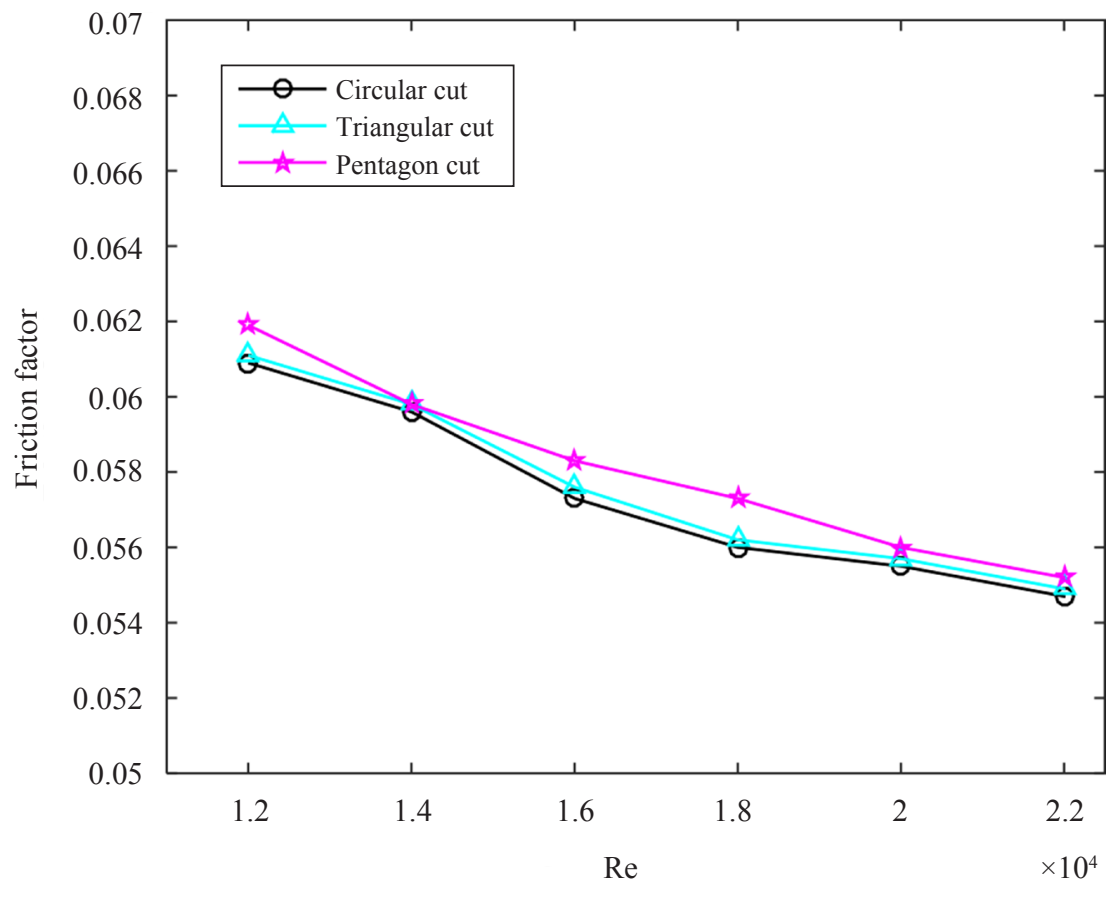

Figure 14: Friction factor vs. Re for different tape inserts.

\subsection{TPF}

Analysis of the present CFD simulation result generally showed that the heat transfer rate is higher when any of the insert is used other than the conventional plain tube, although the increase in heat transfer rate comes with a drawback of increased pressure drop. So, in order to determine the operational conditions under which the heat transfer coefficient augmentation by the use of tape inserts overcomes pressure drop penalty, parameters providing an overall view of the performance enhancement are necessary. In view of this, TPF given by the ratio between the heat transfer enhancement and pressure drop penalty as presented in Equation 37 was used in this study. This approach was considered since it is based on characteristics directly applied by system designers, viz., pumping power, temperature differences and heat exchanger size. This factor has been adopted by researchers to judge the performance of different types of twisted-tape inserts in the previous studies. ${ }^{9,10,14,27}$ Figure 15 display the variation of the TPF with Re for the tube with and without perforated tape inserts. The different tape inserts displayed in the figure are represented in the legend as follows: twisted tape insert (TI), twisted tape with perforated circular shape cut (CC), twisted tape with perforated triangular shape cut (TC) and twisted tape with perforated 
pentagon shape cut $(\mathrm{PC})$. The enhancement performance evaluation in this study was carried out at the selected perforated shape cut (CC, TC, and PC) with fixed area of $56.54 \mathrm{~mm}^{2}$ and twisted tape insert without shape cut perforation (TI) at constant clearance of $0.5 \mathrm{~mm}$ and thickness of $2 \mathrm{~mm}$. The result from the figure revealed that generally, the TPF decrease with increasing Re which is similar to the findings from previous studies. ${ }^{5,14}$ It is also observed that all the perforated shape cut considered in this study yielded a better heat transfer enhancement compared to the twisted tape insert without shape cut perforation (TI) with the perforated triangular shape cut tape insert type resulted to the highest TPF of about 1.68. This behaviour is observed to be more pronounced at lower Re region of the tube. The result of the overall enhancement performance evaluation also revealed a more drastic decrease in the TPF with the use of circular shape compared to other shape cut considered in this study. The drastic decrease in TPF is due to increase in pressure drop resulting from increased fluid velocity increasing the Res and consequently impacting pumping power of the suppose thermal system.

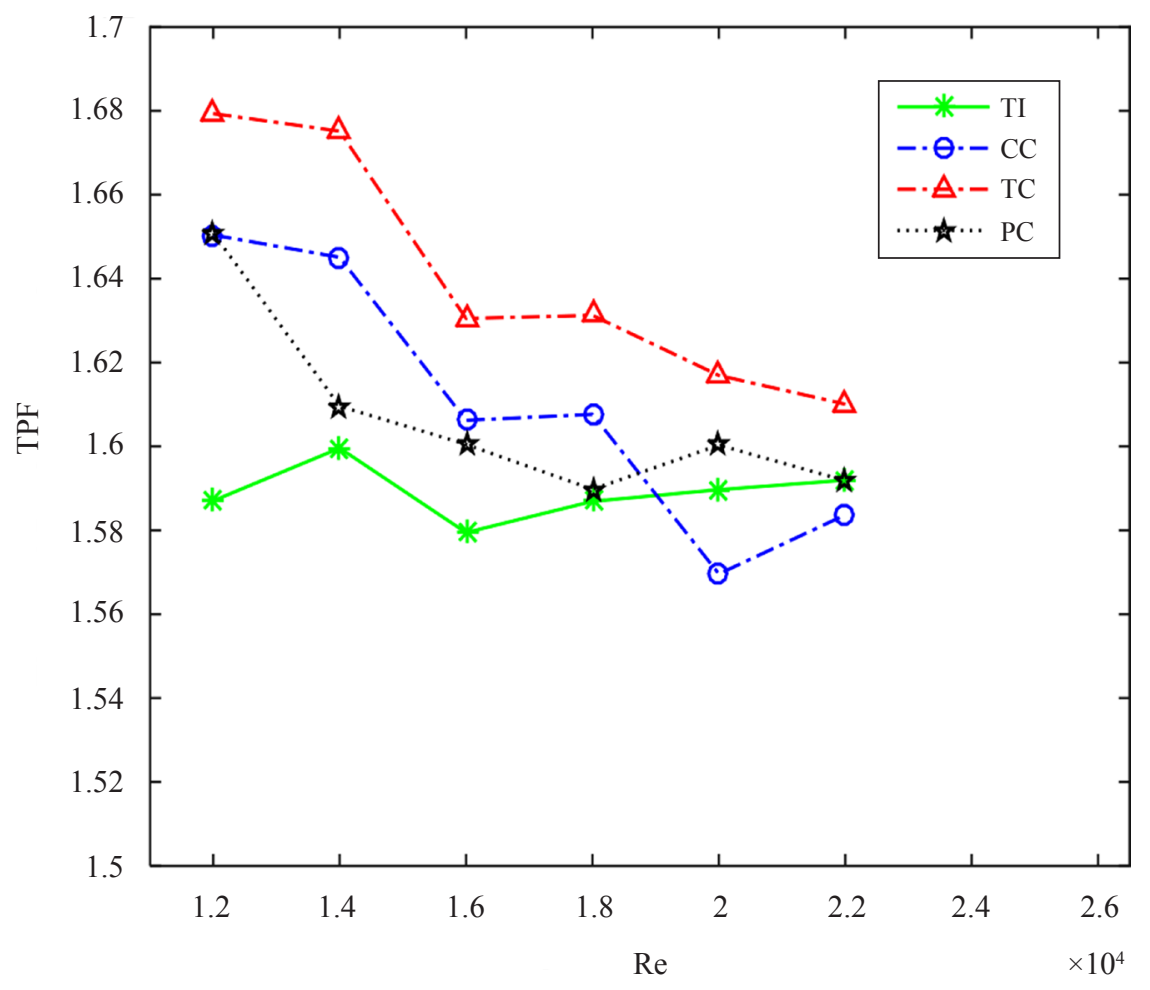

Figure 15: TPF vs. Re for different tape inserts. 
It is also observed that all the perforated shape cut considered in this study yielded a better heat transfer enhancement compared to the twisted tape insert without shape cut. It can be concluded that according to the overall performance of the heat transfer enhancement technique considered in this study, the use of twisted tape with perforated shape cut is more profitable in terms of reduced pumping power and heat exchanger size when applied to the lower region of the evaporator and under lower turbulent Re. It is interesting to highlight that by minimising the heat exchanger size, both the refrigerant inventory located in the heat exchangers and the material used for its manufacture are reduced resulting in lowering its operational costs and importantly, the environmental impact during the thermal system lifetime is also reduced.

\section{CONCLUSION}

The effects of tape insert thickness, tape insert clearance of plain twisted tape inserts and twisted tape inserts with perforation shape cuts (circular, triangular and pentagon) were investigated by numerical simulation to determine how they influence flow in tubes. Generally, results for the different tape inserts considered in this study revealed that tube with twisted tape inserts improves thermal performance compared to tube without twisted tape insert. Further performance improvement was also achieved for the twisted tape with perforated shapes with all the three shapes (circular, triangular and pentagon) produced better thermal performance. Variation of twisted tape thickness in observing fluid flow performance in tubes revealed higher heat transfer coefficient accompanied with high friction factor penalty independent of their thickness when compared to plain tube without insert. It was further observed that despite the increase in friction factor, the highest thickness of $2 \mathrm{~mm}$ is observed with the best thermal-hydraulic performance measured in terms of the TPF evaluation with a value of about 1.65 with Re ranging between 12,000 to 22,000 . Considering the clearance between tube wall and tape, the study revealed that the smaller the clearance, the better the heat transfer performance, with lower friction factor. Best thermal-hydraulic performance is observed for the $0.5 \mathrm{~mm}$ clearance value in terms of TPF evaluation when compared to the other two clearance values investigated in this study. By comparing the different perforated shape of cut on twisted tapes investigated in this study, the triangular shape cut is found to have the best thermal-hydraulic performance with highest TPF of 1.68 while the pentagon and circular shape cuts attained TPF value of 1.66 and 1.65, respectively. According to the preceding analysis on the thermal-hydraulic performance result in terms of TPF evaluation, it can be concluded that the use of twisted tape inserts is suitable to apply and profitable if applied under low turbulent Re. 


\section{ACKNOWLEDGEMENTS}

Authors would like to thank the support from National Research Foundation (NRF) and the Faculty of Engineering and the Built Environment, University of Johannesburg, South Africa for this research.

\section{REFERENCES}

1. Kumar, C. N. \& Murugesan, P. (2012). Review on twisted tapes heat transfer enhancement. Int. J. Eng. Sci. Res., 3(4), 1-8.

2. Mashoofi, N., Pourahmad, S. \& Pesteei, S. M. (2017). Study the effect of axially perforated twisted tapes on the thermal performance enhancement factor of a double tube heat exchanger. Case Stud. Therm. Eng., 10, 161-168, https://doi.org/10.1016/j.csite.2017.06.001.

3. Tamna, S., Kaewkohkiat, Y., Skullong, S. \& Promvonge, P. (2016). Heat transfer enhancement in tubular heat exchanger with double v-ribbed twisted tapes. Case Stud. Therm. Eng., 7, 14-24, https://doi.org/ 10.1016/j.csite.2016.01.002.

4. Chiu, Y. \& Jang, J. (2008). 3D numerical and experimental analysis for thermal-hydraulic characteristics of air flow inside a circular tube with different tube inserts. Appl. Therm. Eng., 29(2/3), 250-258, https://doi.org/10.1016/j.applthermaleng.2008.02.030.

5. Eiamsa-ard, S., Wongcharee, K. \& Sripattanapipat, S. (2009). 3D numerical simulation of swirling flow and convective heat transfer in a circular tube induced by means of loose-fit twisted tapes. Int. Commun. Heat Mass Transf., 36(9), 947-955, https://doi.org/10 .1016/j.icheatmasstransfer.2009.06.014.

6. Mogaji, T. S., Kanizawa, F. T., Bvandarra Filho, E. P. \& Ribatski, G. (2013). Experimental study of the effect of twisted-tape inserts on flow boiling heat transfer enhancement and pressure drop penalty. Int. J. Refrig., 36(2), 504-515, https://doi.org/10.1016/j.ijrefrig.2012 .10 .008 .

7. Zade, N. M., Akar, S., Rashidi, S. \& Esfahani, J. A. (2017). Thermohydraulic analysis for a novel eccentric helical screw tape insert in a three dimensional tube. Appl. Therm. Eng., 124, 413-421, https://doi.org/10.1016/j.applthermaleng.2017.06.036.

8. Suri, R. S., Kumar, A. \& Maithani, R. (2017). Effects of square wings in multiple square perforated twisted tapes on fluid flow and heat transfer of heat exchanger tube. Case Stud. Therm. Eng., 10, 28-43, https://doi.org/10.1016/j.csite.2017.03.002. 
9. Zhang, C., Wang, D., Ren, K., Han, Y., Zhu, Y., Peng, X., Deng, J. \& Zhang, X. (2016). A comparative review of self-rotating and stationary twisted tape inserts in heat exchanger. Renew. Sust. Energ. Rev., 53, 433449, https://doi.org/10.1016/j.rser.2015.08.048.

10. Mwesigye, A., Bello-Ochende, T. \& Meyer, J. P. (2016). Heat transfer and entropy generation in a parabolic trough receiver with wall-detached twisted tape inserts. Int. J. Therm. Sci., 99, 238-257, https://doi.org/ 10.1016/j.ijthermalsci.2015.08.015.

11. Bhuiya, M. M. K., Chowdhury, M. S. U., Saha, M. \& Islam, M. T. (2013). Heat transfer and friction factor characteristics in turbulent flow through a tube fitted with perforated twisted tape inserts. Int. Commun. Heat Mass Transf., 46, 49-57, https://doi.org/10.1016/ j.icheatmasstransfer.2013.05.012.

12. Cengel, Y. A. (2003). Heat transfer: A practical approach. 2nd Ed. New York: McGraw Hill.

13. Saleh, F. A., Habeeb, L. J. \& Maajel, B. M. (2015). Passive heat transfer augmentation technique in a circular tube fitted with different geometry of twisted tape swirl flow generators in laminar flow regime: A review. AASCIT Journal of Energy, 2(5), 61-68.

14. Oni, T. O. (2015). Numerical investigation of heat transfer and fluid flow in tubes induced with twisted tape inserts. PhD diss., University of Glasgow.

15. Bhuiya, M. M. K., Chowdhury, M. S. U., Ahamed, J. U. \& Azad, A. K. (2015). Heat transfer performance evaluation and prediction of correlation for turbulent flow through a tube with helical tape inserts at higher Reynolds number. Heat Mass Transfer, 52, 1219-1230, https://doi.org/10.1007/s00231-015-1643-y.

16. Oni, T. O. \& Paul, M. C. (2016). Numerical investigation of heat transfer and fluid flow of water through a circular tube induced with divers' tape inserts. Appl. Therm. Eng., 98, 157-168, https://doi.org/10.1016/ j.applthermaleng.2015.12.039.

17. Oni, T. O. \& Paul, M. C. (2015). CFD investigation of the impacts of variation in geometry of twisted tape on heat transfer and flow characteristics of water in tubes. Heat Transfer: Asian Research, 45(5), 482-498, https://doi.org/10.1002/htj.21216.

18. Kumar, A., Sureka, U. \& Kumar, S. (2018). Numerical analysis of heat transfer enhancement in a double pipe heat exchanger with a holed twisted tape. MATEC Web Conf., 144, 04012, https://doi.org/10.1051/ matecconf/201814404012. 
19. Versteeg, H. K. \& Malalasekera, W. (2017). An introduction to computational fluid dynamics: The finite volume method. 2nd Ed. Harlow, England: Pearson/Prentice Hall.

20. ANSYS. (2006). ANSYS FLUENT help manual, release 16.1. Canonsburg, PA: ANSYS, Inc.

21. Kays, W. M. \& Crawford, M. E. (1980). Convection heat and mass transfer. 2nd Ed.New York: McGraw Hill.

22. Patankar, S. V. \& Spalding, D. B. (1972). A calculation procedure for heat, mass and momentum transfer in three dimensional parabolic flows. Int. J. Heat Mass Transf., 15(10), 1787-1806, https://doi.org/10.1016/ 0017-9310(72)90054-3.

23. Petukhov, S. (2015). Heat transfer and friction in turbulent pipe flow with variable physical properties. In J. P. Hartnett \& T. F. Irvine, Jr. (eds.), Advances in heat transfer. New York: Academic Press, 503-564.

24. Blasius, H. (1908). Grenzschichten in flussigkeiten mit kleiner reibung. Z. Angew. Math. Phys., 56, 1-37.

25. Gnielinski, V. (1976). New equations for heat and mass transfer in turbulent pipe and channel flow. Int. Chem. Eng., 16(2), 359-368.

26. Dittus, F. W. \& Boelter, L. M. K. (1930). Heat transfer in automobile radiators of the tubular type. Berkeley, CA: University of California Press, 443-461.

27. Yadav, R. J. \& Padalkar, A. S. (2012). CFD analysis for heat transfer enhancement inside a circular tube with half-length upstream and halflength downstream twisted tape. J. Chem. Thermodyn., 2012, 580593, https://doi.org/10.1155/2012/580593. 